\title{
Interactive comment on "A powerful lidar system capable of one-hour measurements of water vapour in the troposphere and the lower stratosphere as well as the temperature in the upper stratosphere and mesosphere" by Lisa Klanner et al.
}

\section{Anonymous Referee \#3}

Received and published: 11 August 2020

Review for "A powerful lidar system capable of one-hour measurements of water vapour in the troposphere and the lower stratosphere as well as the temperature in the upper stratosphere and mesosphere"

This manuscript describes a high-power Raman lidar system has been installed at Schneefernerhaus (Garmisch-Partenkirchen, Germany) at $2675 \mathrm{~m}$ a.s.l., at the side of an existing wide-range differential-absorption lidar (DIAL). An industrial $\mathrm{XeCl}$ laser was 
modified for linearly polarized single-line operation at an average power of about $180 \mathrm{~W}$. This high power and a 1.5-m-diameter receiver allow us to extend the operating range for water-vapour sounding to $20 \mathrm{~km}$ for a measurement time of just one hour, at an uncertainty level of the mixing ratio of 1 to $2 \mathrm{ppm}$. The lidar was successfully validated with a balloon-borne cryogenic frost-point hygrometer (CFH). In addition, temperature measurements to altitudes around $87 \mathrm{~km}$ were demonstrated for one hour of signal averaging. The system has been calibrated with the DIAL, the CFH and radiosondes.

General Comments:

In general this manuscript describes the lidar system in an immense detail. At times it can get confusing as to which lidar system or which component is being described.

Consider alternate word choice for the term 'powerful' in the title or 'stronger' in the abstract, they are both ambiguous.

The introduction is not logically presented as many key words are missing from sentences and there is no consistent message. Consider adding a key figure or illustration that better gives the reader a perspective on where the lidar would help understand either trends or process studies (or both). There are statements without adequate referencing. This can and should be related back to the atmospheric case study to better support the importance of the vertical lidar profile.

The introduction is also quite long and some is described in the authors previous 2008 work (https://doi.org/10.1364/AO.47.002116). Consider shortening or directing the reader to this publication for more details regarding the DIAL.

In general the lidar description has very useful information but is organized as one would take field notes. There needs to be some explanation as to why many of these parameters are important. It's also not clear that the thin film polarizer or Raman cell (SRS) are actually used in the experiment as there is no final outcome described. There are too many varied parameters (focal length, rep rate, input power, cell length)

Printer-friendly version

Discussion paper

Interactive comment 
for the reader to come away with any conclusion.

Additional water vapor lidar references include : https://doi.org/10.1175/1520AMTD 0426(1995)012<1177:ACOWVM>2.0.CO;2

Technical Comments: P1L23 - disregard the first use of UTLS P1L26-29 - provide further references for these statements P1L29 - Write out NCEP in first use P3L28 Is the lidar used in daytime or during nighttime? Or DIAL during the day and Raman system during the night?

Figure $1 / 3$ - can these be combined?

Figure 13: How is the WV calibration calculated for this night? For instance, it looks as a scaled factor could be applied to the WV profile. What is the difference at $2 \mathrm{~km}$ caused by?

Consider reducing the number of individual water vapor comparison profiles or make an aggregate summary plot. How many measurements of WV are there with the new system? Feb 2019 is the most compelling of the case studies as an excellent comparison with the $\mathrm{CFH}$.

Conclusions: How frequent are the temperature measurements? Is this system automated?

Interactive comment on Atmos. Meas. Tech. Discuss., doi:10.5194/amt-2020-90, 2020.

Discussio 